\title{
Transanal Endoscopic Microsurgery (TEM) for Rectal Neoplasms
}

\author{
Manuel Ferrer-Márquez*, Ángel Reina-Duarte, Francisco Rubio-Gil, \\ Ricardo Belda-Lozano, Antonio Álvarez-García \\ Departments of Colorectal Surgery, General Surgery, Torrecárdenas Hospital, Almería, Spain \\ Email: " manuferrer78@hotmail.com
}

Received December 14, 2011; revised February 10, 2012; accepted March 23, 2012

\begin{abstract}
Introduction: The abdominal approach for the treatment of rectal tumors is associated with a considerable rate of morbidity. Transanal Endoscopic Microsurgery (TEM) is an alternative technique that is less invasive than radical surgery, and therefore has a lower associated morbidity. Moreover, with proper patient selection, TEM presents oncological outcomes comparable to radical surgery. The aim of this study is to review our results obtained with TEM and discuss its role in the treatment of malignant rectal lesions. Patients and Methods: A prospective descriptive study from June 2008 until February 2011. The indications for TEM were: early rectal neoplastic lesions $\left(\mathrm{T}_{1} \mathrm{~N}_{0} \mathrm{M}_{0}\right)$ with good prognostic factors; neoplastic lesions in more advanced stages in selected patients (high surgical risk, refusal of radical surgery or stoma, and palliative intention). Results: Resection by TEM was performed on 19 patients. The average hospital stay was 5.7 days with an associated morbidity of $16.7 \%$. $\mathrm{R}_{0}$ resection was $88.8 \%$. During the follow-up of 15 (3 - 31) months, no recurrence has been shown. Conclusions: TEM is a safe and effective procedure for the treatment of selected early malignant rectal lesions and is associated with low morbidity. It is a therapeutic strategy based on a multidisciplinary team, careful patient selection, an audited surgical technique and a strict follow-up protocol.
\end{abstract}

Keywords: Transanal Endoscopic; Microsurgey; TEM; Rectal Neoplasms

\section{Introduction}

Surgical treatment of rectal tumors has traditionally required an abdominal approach (open or laparoscopic), which includes the performance of sphincter-preservation interventions (low or ultra-low resection) or abdominoperineal resections; all depending on the location and infiltration of the lesion. These radical interventions, in addition to sometimes requiring the creation of a stoma (permanent or temporary), are also burdened with a not insubstantial mortality rate and a considerable frequency of complications such as genitourinary disorders, sexual dysfunction and abnormalities in defecation [1-4].

One alternative for the treatment of certain rectal lesions has been the so-called "classic" endoanal resection described by Parks in 1970 [5], which preserves sphincter function and is associated with low morbimortality. Its limitation is the height of the lesion $(7-8 \mathrm{~cm}$ from the anal margin), as well as technical difficulties involving less control in the margins of resection [6-8].

In the 1980s, Buess et al. [9] described Transanal Endoscopic Microsurgery (TEM) in order to solve these

${ }^{*}$ Corresponding author. problems. This technique allows the resection of lesions up to $18-20 \mathrm{~cm}$, the maximum reach of a specificallydesigned rectoscope that, incorporating a stereoscopic optic for three-dimensional vision and a system of $\mathrm{CO}_{2}$ insufflation-exsufflation, maintains a stable pneumorectum that allows for a better visualization of the rectal ampulla and, therefore, a more controlled resection. Therefore, TEM-associated with low (4\% - 24\%) and, in most cases, irrelevant morbidity [10]-is a safe technique from both oncological and surgical points of view.

However, the key point of TEM is the correct selection of patients, which means that the indications for the procedure must be precise. Currently, the indications for this technique are not limited to benign lesions. Thus, TEM is also the technique of choice for early malignant lesions susceptible to local treatment and can even, as discussed below, be used in very select cases for more advanced malignant lesions. Recently, the indications for TEM have been expanding beyond rectal tumors; it is being used for the treatment of complications like stenosis, fistulae, and retrorectal tumors, among others $[11,12]$.

Next, we report our results regarding the treatment of selected rectal neoplastic lesions by TEM. 


\section{Patients and Methods}

A prospective descriptive study including all patients who underwent TEM for the treatment of selected rectal neoplastic lesions from June 2008 until February 2011. Patients referred to our office are studied in detail through a complete medical history, rectal examination, rigid rectoscopy, colonoscopy, pelvic magnetic resonance (MRI), endoanal ultrasound and abdominal CT scan. In our study, the indications for performing TEM are as follows: early rectal neoplastic lesions $\left(\mathrm{T}_{1} \mathrm{~N}_{0} \mathrm{M}_{0}\right)$ with good prognostic factors; neoplastic lesions with more advanced stages in selected patients (those with high surgical risk, refusal of radical surgery or stoma and palliative intention).

\subsection{Surgical Technique}

All patients undergo mechanical preparation the day before surgery, and are given the standard antibiotic and antithrombotic prophylaxis for colorectal surgery. The procedure is performed under general anesthesia and bladder catheterization. Patient positioning will depend on the location of the tumor, as TEM should be performed with the lesion at the bottom part of the rectoscope. Therefore, when the lesion is posterior, the patient is placed in lithotomy position; if it is found in the anterior rectal wall, the patient is placed in a prone decubitus position; if it is the lateral, the patient is placed in the corresponding lateral decubitus position.

We perform routine rigid rectoscopy in the operating room in order to confirm the nature of the lesion. The work is done with pneumorectum at constant pressure thanks to the presence of the $\mathrm{CO}_{2}$ insufflator-exsufflator. Once the lesion is visualized, the rectoscope is fixed through the adjustable Martin arm. Subsequently, the tubing set and the stereoscopic and assistance optics are mounted. Dissection begins by marking, with an electric scalpel, the theoretical margins of resection, which will be $10 \mathrm{~mm}$. Later, resection will be performed with an ultrasonic scalpel. Once the lesion is excised, the area is irrigated with povidone-iodine diluted in saline solution to $1 \%$. We carry out the closure of the defect (whenever possible) with $3 / 0$ absorbable monofilament, with a cylindrical needle, performing a running suture secured with silver clips. Once the suture is completed, we check hemostasis and recommence irrigation with povidone and saline solution (Figures $\mathbf{1}$ and 2).

An adequate pneumorectum is necessary for the correct visualization of the lesion. Therefore, once the intervention is finished, we subjectively conduct an assessment of the pneumorectum on a scale from 1 (very bad) to 10 (excellent). Thus, we classify the pneumorectum by: optimal $(8-10)$, acceptable $(5-7)$ and suboptimal $(\leq 4)$.

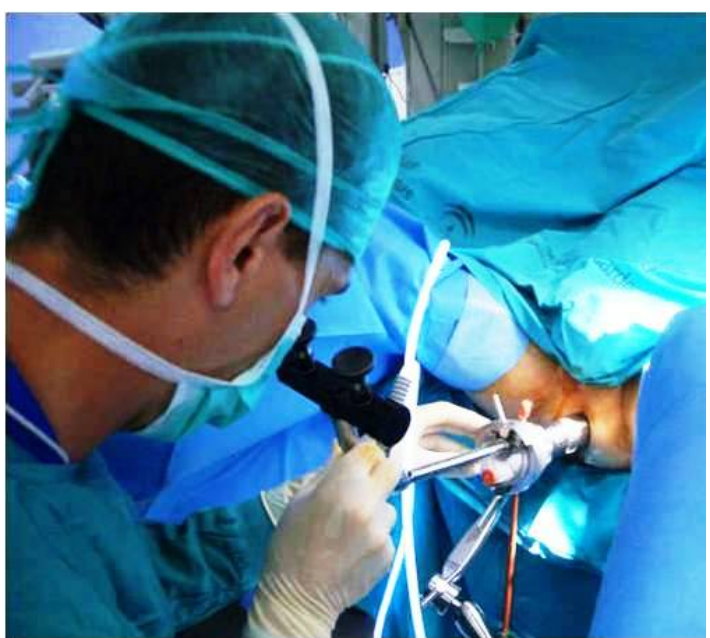

Figure 1. Rectoscope fixed through the adjustable Martin arm.

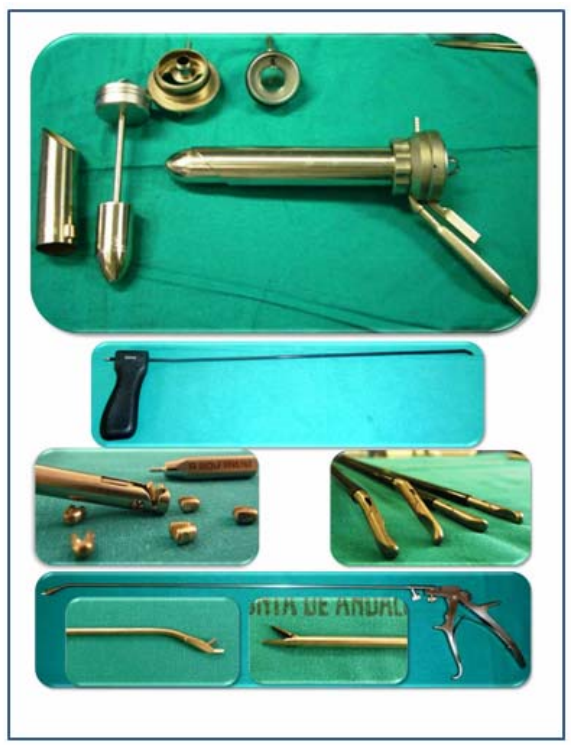

Figure 2. TEM instrumental.

A crucial point in this type of surgery is the pathologist's study. After the excision of the lesion, it is fixed to a cork by needles that prevent its retraction. Then, it is assessed by the anatomopathologist in the operating room, before its definitive study. In malignant lesions, Kikuchi classification [13] is performed for sessile lesions and Haggitt classification [14] for polypoid lesions.

\subsection{Postoperative Management and Follow-Up}

It is unnecessary to perform the so-called functional protective colostomy. The patient's tolerance of liquids begins the next day, and is gradually increased if the patient can tolerate it.

After the anatomopathological study, those patients with $T_{2}$ or $T_{1}$ lesions with unfavorable criteria (vascular 
or lymphatic invasion, poorly differentiated lesions, Kikuchi $\mathrm{Sm}_{3}$ or positive resection margins) will be submitted in oncological committee for radical surgery or, in select cases, adjuvant treatment. The follow-up for these patients will be as follows: during the two first years, rectoscopy and tumor markers (CEA and Ca19.9) will be performed every 4 months. From the third to the fifth year, those tests will be performed every 6 months. Check-ups will be accompanied annually by abdominal CT scan and colonoscopy.

\section{Results}

A total of 18 patients -8 women and 10 men, with a mean age of 68 years $(48-89)$ underwent surgery between June 2008 and February 2011. The preoperative diagnosis was adenoma in 3 patients and carcinoma in 15 . Among these last patients, five were classified preoperatively as $\operatorname{urT}_{3}$, and four as $\operatorname{urT}_{2}$ (Table 1). This indicated TEM for several reasons: six of them as palliative treatment because of the high surgical risk they would have undertaken in case of radical resection and three patients for refusing to assume the morbimortality associated with radical resection and the possibility of stoma.

All patients were operated on by two surgeons. The mean operating time was $118 \pm 46(60-220)$ minutes (Figure 3). The mean height of the lesions was $6.7 \pm 3.5$ $(1-13) \mathrm{cm}$. The location was posterior in $33.3 \%$, anterior in $22.2 \%$, right side in $16.7 \%$ and left side in $27.8 \%$. The pneumorectum was considered to be optimal in $55.6 \%$ of the cases, acceptable in $27.7 \%$, and suboptimal in $16.7 \%$. No differences have been observed between patient position or lesion height and the quality of the pneumorectum.

Full-thickness resection was performed in $100 \%$ of the cases. During dissection of pieces, they were fragmented in one patient (5.5\%); the rest were obtained as complete piece. Suture of the defect was performed in $66.6 \%$ of the cases $(91 \%$ complete sutures and $9 \%$ partial sutures). The mean area of the lesion was $14.3 \pm 10.8(2-39) \mathrm{cm}^{2}$.

Table 1. Pre- and postoperative diagnosis.

\begin{tabular}{|c|c|c|c|}
\hline Preoperative diagnosis & & Postoperative diagnosis & \\
\hline Benign & & Benign & \\
\hline Adenoma & 3 & Adenoma & 0 \\
\hline Malignant & & Malignant & \\
\hline Adenocarcinoma urT $_{1}$ & 6 & Adenocarcinoma $\mathrm{pT}_{1}$ & 9 \\
\hline Adenocarcinoma $\mathrm{urT}_{2}$ & 4 & $\mathrm{Sm}_{1}$ & 3 \\
\hline \multirow[t]{4}{*}{ Adenocarcinoma $\mathrm{urT}_{3}$} & 5 & $\mathrm{Sm}_{2}$ & 3 \\
\hline & & $\mathrm{Sm}_{3}$ & 2 \\
\hline & & Adenocarcinoma $\mathrm{pT}_{2}$ & 4 \\
\hline & & Adenocarcinoma $\mathrm{pT}_{3}$ & 5 \\
\hline
\end{tabular}

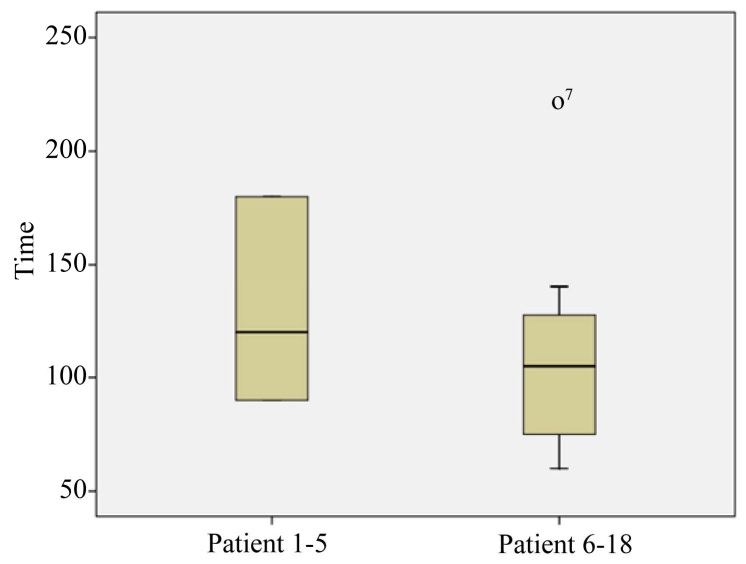

Figure 3. Operation time.

We have presented three entries in abdominal cavity, two of which required reconversion to laparotomy; we performed a low anterior resection in one of the cases, and a Hartmann procedure in another. It was, in both cases, a palliative treatment in patients with high surgical risk and in whom the characteristics of the defect did not allow a safe repair by TEM. In the third case, the defect was closed by a continuous suture on two planes. Therefore, the rate for reconversion to laparotomy was $11.1 \%$.

The average hospital stay was 5.7 (2 - 25) days. Morbidity was $16.7 \%$, with two minor complications and one major complication (Table 2). The minor complications were two self-limited rectal bleeding cases that did not require transfusion. One patient was readmitted one week after discharge because of bleeding, requiring surgical revision and control with hemostatic stitching in the suture line. This was a patient at high surgical risk who underwent TEM after preoperative radiotherapy and presented with significant actinic proctitis. One patient presented with postoperative pneumoperitoneum without clinical repercussions.

The mean follow-up period of the patients was 15 (3 31) months. Incidents recorded during that time were: two patients who presented mild gas incontinence from which they recovered 3 months after surgery, and a patient who presented with severe defecation urgency, currently being treated with biofeedback.

Eighteen patients had a postoperative diagnosis of carcinoma. The stage was $\mathrm{pT}_{1}$ in nine patients (three patients $\mathrm{Sm}_{1}$, three patients $\mathrm{Sm}_{2}$, two patients $\mathrm{Sm}_{3}$, and one patient Haggitt 4), $\mathrm{pT}_{2}$ in four patients, and $\mathrm{pT}_{3}$ in five patients (Table 1). $\mathrm{R}_{0}$ resection was confirmed in sixteen patients $(88.8 \%)$. The two patients with $\mathrm{R}_{1}$ resections were two patients with $T_{3}$ preoperative diagnosis who underwent TEM as palliative procedure. The patient who was diagnosed with $\mathrm{pT}_{1}$ adenocarcinoma (Haggitt 4 ) was a 56-year woman, who also presented with poor prognostic factors (neural and vascular invasion). An oncological committee decided to attempt to save her with 
Table 2. Morbidity after TEM.

\begin{tabular}{lc}
\hline Postoperative morbidity & $\mathrm{n}(\%)$ \\
\hline Minor & \\
$\quad$ Rectal bleeding & $2(11,1)$ \\
Major & \\
$\quad$ Bleeding requiring intervention & $1(5,6)$ \\
Long term & \\
$\quad$ Fecal incontinence (recovered) & $2(11,1)$ \\
$\quad$ Major fecal incontinence & $1(5,6)$ \\
\hline
\end{tabular}

radical surgery (low anterior resection). We decided to follow-up with the patients with $\mathrm{pT}_{1}$ adenocarcinoma $\left(\mathrm{Sm}_{3}\right.$, in one case because of the patient's characteristics (high surgical risk) and in another because of the patient's refusal of radical surgery. Among patients with definitive $\mathrm{pT}_{2}$ diagnosis, two received postoperative radiotherapy (RT) and the other two underwent radical resection (intraoperative conversion for entry into the cavity). Among patients with $\mathrm{pT}_{3}$ diagnosis, three received postoperative radiotherapy and the other two were palliative patients who died during the follow-up period for reasons unrelated to surgery. During the follow-up period, no local recurrence has been shown.

\section{Discussion}

Abdominal surgery has traditionally been considered the most important tool for the treatment of rectal lesions. However, both low anterior resection and abdominoperineal amputation are associated with a significant morbimortality [1-4]. Moreover, the traditional endoanal resection (TAE) is limited by the height of the tumor in relation to the anal margin and presents technical difficulties that cause, in many cases, an insufficient exposure of the lesion and therefore, an increase in the recurrence rate [6-8]. Transanal Endoscopic Microsurgery utilizes very specific equipment (magnification and insufflation) that permits greater accessibility, better visualization and, therefore, a more precise resection than TAE. Furthermore, TEM can reach lesions in the middle and upper rectum that are impossible to reach with $\mathrm{TAE}[15,16]$.

However, it is important to note that TEM does not change the indication criteria for the resection of rectal lesions. In our opinion, indications for TEM are as follows: 1) elective surgical treatment for benign rectal tumors; 2) malignant tumors in early stages $\left(\mathrm{T}_{1} \mathrm{~N}_{0}\right)$ with good prognostic criteria; 3 ) associated adjuvant or neoadjuvant treatment in select cases of well- or moderatelydifferentiated small-size superficial $\operatorname{urT}_{2} / \mathrm{T}_{3} \quad \mathrm{urN}_{0}$ rectal carcinomas in elderly patients or those with significant risk factors or in the context of a controlled clinical trial; and 4) palliative treatment in patients with more advanced stages of disease who are at high surgical risk or refuse radical surgery. Moreover, those $\mathrm{N}_{0}$ rectal lesions in which there is discrepancy in the $\mathrm{T}$ stage can indicate a complete excisional biopsy, indicating subsequent radical surgery in case of $T_{1}$ lesions with bad prognosis or $T_{2}$ $\mathrm{T}_{3}$ lesions [17,18].

Regarding surgical technique, we use an ultrasonic scalpel in all resections as it permits good hemostasis control, facilitates vision of the section area and, therefore, decreases surgical time [19]. Recently, we have

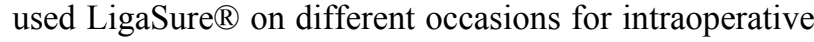
decapitation of bulky lesions, allowing a better assessment of the pedicle and its resection margins.

An important aspect is whether, once the lesion is excised, the defect should be sutured systematically (whenever possible). This is a point of some controversy. Ramírez et al. [20], in a randomized study, conclude that results are not affected by whether or not the defect is sutured. On the other hand, other authors defend systematic closure in order to avoid stenosis problems and postoperative bleeding [10]. In our opinion, it is advisable to attempt the suture systematically, not only for the reasons given by Parc Taulí's [10] group but also because we consider it of great importance to obtain the skill necessary to suture the defect when its closure is required (entry into cavity).

Mean operating time in our series was $118 \pm 46(60$ 220) minutes. Given that the first cases were part of the learning curve, we can observe that operating time decreased although not significantly, due to the sample size after patient number 5 (132 vs. 110 minutes) (Figure 3).

In our series, we encountered intraoperative difficultties in three patients, two of whom required laparotomy because they presented a peritoneal opening that was not susceptible to repair by TEM. Bretagnol et al. [21] report a $12 \%$ rate of technical difficulties, including intraperitoneal perforation, pneumorectum leakage and bleeding. Gavagn [22] and Ramwell et al. [23] conclude that entry into the peritoneum does not necessarily increase the risk of morbidity.

Our study confirms that it is a safe procedure with low morbimortality. Our figures are found to be within the range published by other series $(2 \%-30 \%)$ [21,24-29], being mostly minor complications which are solved with conservative treatment. Although urinary retention is the most common complication in other studies, our main postoperative complication was bleeding, which presented in three patients, one of whom required surgical revision.

Regarding early rectal cancer, the main factor limiting the effectiveness of local treatment is the degree of lymph node invasion. Invasion depth in the rectal wall, degree of differentiation, and vascular, lymphatic and neural invasions are independent factors of nodal metastasis. T stage estimates the probability of lymphatic dis- 
ease, which ranges between 0 and $15 \%$ for $\mathrm{T}_{1}$ tumors, and from $16 \%$ to $28 \%$ in $\mathrm{T}_{2}$ tumors. Therefore, strict selection criteria, along with a favorable surgical technique involving the entire wall and free margins, are essential for obtaining good results.

Different series have published excellent results using TEM for the treatment of $\mathrm{T}_{1}$ rectal cancer. Floyd et al. [30] describe 53 patients with $\mathrm{T}_{1}$ rectal cancer, with a mean follow-up period of 2.8 years, finding $7.5 \%$ recurrence. Similar results in terms of low recurrences have been described in other published series [17,31-35]. Other studies comparing TEM against radical resection for $\mathrm{T}_{1}$ low rectal cancer do not show significant differences in regards to local recurrences and survival, while they do, in terms of postoperative morbidity, favor TEM [36,37]. Nine patients with $T_{1}$ rectal cancer who have presented no local recurrence during follow-up are included in our study. During the histological study, we favor measuring the degree of submucosal invasion (Kikuchi [13]), as we consider patients with $\mathrm{pT}_{1} \mathrm{Sm}_{3}$ lesions to have a significantly higher risk of lymphatic dissemination than those with less submucosal invasion $(23 \%$ $\mathrm{Sm}_{3}$ vs. 3 and $8 \%$ for $\mathrm{Sm}_{1}$ and $\mathrm{Sm}_{2}$, respectively) [38]. Although not all authors do, we believe that it is necessary to consider radical surgery for these patients. This is why this type of patient goes through oncological committee after surgery to evaluate adjuvant treatment or radical surgery.

More controversial is the role of TEM in the treatment of $T_{2}$, or superficial $T_{3}$, rectal cancers, given the high probability of nodal metastasis that these tumors present. Currently, except in the context of controlled clinical trials, radical surgery is the treatment of choice. However, some authors have shown favorable results in selected $\mathrm{T}_{2}$ patients receiving adjuvant treatment after TEM [28,39].

An alternative for the treatment of certain advanced adenocarcinomas may be neoadjuvant therapy followed by local excision. The group of Lezoche et al. [40] utilizes preoperative radiotheraphy followed by TEM in selected patients with $\mathrm{T}_{2}$ and $\mathrm{T}_{3} \mathrm{~N}_{0}$ lesions lower than 3 $\mathrm{cm}$. Survival at 90 months was $89 \%$, with only $4.1 \%$ of local recurrence after 55 months of follow-up. Within the same group, Guerrieri et al. [41], analyze their results in $66 \mathrm{~T}_{2}$ and $24 \mathrm{~T}_{3}$ patients, with $4.1 \%$ local recurrence, and survival rates of $90 \%$ in $\mathrm{T}_{2}$ and $77 \%$ in $\mathrm{T}_{3}$. Effectiveness of neoadjuvant therapy in $\mathrm{T}_{2} \mathrm{~N}_{0}$ adenocarcinomas followed by local treatment with TEM is unknown. Therefore, more controlled studies that show safe and secure results are needed. We are currently part of a prospective, multicenter, controlled and randomized clinical trial which aims to shed light on this controversial issue. This study, sponsored by Dr. Serra Aracil, from Parc Taulís group (Sabadell), has a main objective of analyzing the results of local recurrence at 2 years of follow-up in patients with $\mathrm{T}_{2}-\mathrm{T}_{3 \mathrm{~s}}$ (superficial), $\mathrm{N}_{0}, \mathrm{M}_{0}$ lesions, who are treated with preoperative chemoradiotherapy and TEM, compared to those who are treated with conventional radical surgery (total mesorectal excision).

\section{Conclusion}

TEM is a minimally invasive, safe and effective procedure for the treatment of selected early malignant rectal lesions. It is associated with a low morbimortality, in many cases avoiding the consequences of radical surgery. In any case, TEM is not just a technique for local surgery but a therapeutic strategy as well, based on a multidisciplinary team (gastroenterologists, radiologists, pathologists, anesthesiologists, oncologists, nurses and colorectal surgeons), careful patient selection, an audited surgical technique and a strict follow-up protocol.

\section{REFERENCES}

[1] W. L. Law and K. W. Chu, "Anterior Resection for Rectal Cancer with Mesorectal Excision: A Prospective Evaluation of 622 Patients," Annals of Surgery, Vol. 240, No. 2, 2004, pp. 260-268. doi:10.1097/01.sla.0000133185.23514.32

[2] W. E. Enker, N. Merchant, A. M. Cohen, N. M. Lanouette, C. Swallow, J. Guillem, et al., "Safety and Efficacy of Low Anterior Resection for Rectal Cancer: 681 Consecutive Cases from a Specialty Service," Annals of Surgery, Vol. 230, No. 4, 1999, pp. 544-552. doi:10.1097/00000658-199910000-00010

[3] C. A. Maurer, "Urinary and Sexual Function after Total Mesorectal Excision," Recent Results Cancer Research, Vol. 165, 2005, pp. 196-204. doi:10.1007/3-540-27449-9_21

[4] A. Chiappa, R. Biffi, E. Bertani, A. P. Zbar, U. Pace, C. Crotti, et al., "Surgical Outcomes after Total Mesorectal Excision for Rectal Cancer," Journal of Surgical Oncology, Vol. 94, No. 3, 2006, pp. 182-193. doi: $10.1002 /$ jso. 20518

[5] A. G. Parks, "A Technique for the Removal of Large Villous Tumours in the Rectum," Proceedings of the Royal Society of Medicine, Vol. 63, 1970, pp. 89-91.

[6] R. Mittal, B. Perakath, S. Chase, M. R. Jesudason and S. Nayak, "Transanal Excision of Anorectal Lesions-A Single Centre Experience," Trop Gastroenterology, Vol. 31, No. 1, 2010, pp. 65-68.

[7] A. Mellgren, P. Sirivongs, D. A. Rothenberger, R. D. Madoff and J. García-Aguilar, "Is Local Excision Adequate Therapy for Early Rectal Cancer?" Diseases of the Colon \& Rectum, Vol. 43, 2000, pp. 1064-1074. doi:10.1007/BF02236551

[8] D. A. Rothenberger and J. Garcia-Aguilar, "Role of Local Excision in the Treatment of Rectal Cancer," Seminars in Surgical Oncology, Vol. 19, 2000, pp. 367-375. doi:10.1002/ssu.7

[9] G. Buess, R. Theiss, M. Gunther, F. Hutterer and H. 
Pilchmaier, "Endoscopic Surgery in the Rectum," Endoscopy, Vol. 17, 1985, pp. 31-35 doi:10.1055/s-2007-1018451

[10] X. Serra, J. Bombardó, L. Mora, M. Alcántara, I. Ayguavives and S. Navarros, "Microcirugía Endoscópica Transanal (TEM). Situación Actual y Expectativas de Futuro," Cir Esp, Vol. 80, No. 3, 2006, pp. 123-132. doi:10.1016/S0009-739X(06)70940-X

[11] X. Serra Aracil, C. Gómez Díaz, J. Bombardó Junca, L. Mora López, M. Alcántara Moral, I. Ayguavives Garnica, et al., "Surgical Excision of Retrorectal Tumour Using Transanal Endoscopic Microsurgery," Colorectal Disease, Vol. 12, No. 6, 2010, pp. 594-595. doi:10.1111/j.1463-1318.2009.02126.x

[12] P. Vavra, J. Dostalik, M. Vavrova, P. Gunkova, M. Pai, A. El-Gendi, et al., "Transanal Endoscopic Microsurgery: A Novel Technique for the Repair of Benign Rectovaginal Fistula," Surgeon, Vol. 7, No. 2, 2009, pp. 126-127. doi:10.1016/S1479-666X(09)80031-0

[13] R. Kikuchi, M. Takano, K. Takagi, N. Fujimoto, R. Nozaki and T. Fujiyoshi, "Management of Early Invasive Colorectal Cancer. Risk of Recurrence and Clinical Guidelines," Diseases of the Colon \& Rectum, Vol. 38, No. 12, 1995, pp. 1286-1295. doi:10.1007/BF02049154

[14] R. C. Haggitt, R. E. Glotzbach, E. E. Soffer and L. D. Wruble, "Prognostic Factors in Colorectal Carcinomas Arising in Adenomas: Implications for Lesions Removed by Endoscopic Polypectomy," Gastroenterology, Vol. 89, No. 2, 1985, pp. 328-336.

[15] P. F. Middleton, L. M. Sutherland and G. J. Maddern, "Transanal Endoscopic Microsurgery: A Systematic Review," Diseases of the Colon \& Rectum, Vol. 48, No. 2, 2005, pp. 270-284. doi:10.1007/s10350-004-0804-8

[16] D. Christoforidis, H. M. Cho, M. R. Dixon, A. F. Mellgren, R. D. Madoff and C. O. Finne, "Transanal Endoscopic Microsurgery versus Conventional Transanal Excision for Patients with Early Rectal Cancer," Annals of Surgery, Vol. 249, No. 5, 2009, pp. 776-782. doi:10.1097/SLA.0b013e3181a3e54b

[17] T. J. Saclarides, "TEM/Local Excision: Indications, Techniques, Outcomes, and the Future," Journal of Surgical Oncology, Vol. 96, No. 8, 2007, pp. 644-650. doi:10.1002/jso.20922

[18] A. R. Dias, C. S. Nahas, C. F. Marques, S. C. Nahas and I. Cecconello, "Transanal Endoscopic Microsurgery: Indications, Results and Controversies," Techniques in Coloproctology, Vol. 13, No. 2, 2009, pp. 105-111. doi:10.1007/s10151-009-0466-6

[19] I. D. Ayodeji, W. C. Hop, G. W. Tetteroo, H. J. Bonjer and E. J. de Graaf, "Ultracision Harmonic Scalpel and Multifunctional Tem400 Instrument Complement in Transanal Endoscopic Microsurgery: A Prospective Study," Surgical Endoscopy, Vol. 18, No. 12, 2004, pp. 17301737. doi:10.1007/s00464-003-9331-2

[20] J. M. Ramírez, V. Aguilella, D. Arribas and M. Martínez, "Transanal Full-Thickness Excision of Rectal Tumours: Should the Defect Be Sutured? A Randomized Controlled Study," Colorectal Disease, Vol. 4, 2002, pp. 51-55. doi:10.1046/j.1463-1318.2002.00293.x

[21] F. Bretagnol, A. Merrie, B. George, B. F. Warren and N. J. Mortensen, "Local Excision of Rectal Tumours by Transanal Endoscopic Microsurgery," British Journal of Surgery, Vol. 94, No. 5, 2007, pp. 627-633. doi:10.1002/bjs.5678

[22] J. A. Gavagan, M. H. Whiteford and L. L. Swanstrom, "Full-Thickness Intraperitoneal Excision by Transanal Endoscopic Microsurgery Does Not Increase Short-Term Complications," American Journal of Surgery, Vol. 187, 2004, pp. 630-634. doi:10.1016/j.amjsurg.2004.01.004

[23] A. Ramwell, J. Evans, M. Bignell, J. Mathias and J. Simson, "The Creation of a Peritoneal Defect in Transanal Endoscopic Microsurgery Does Not Increase Complications," Colorectal Disease, Vol. 11, No. 9, 2009, pp. 964-966. doi:10.1111/j.1463-1318.2008.01719.x

[24] M. E. Allaix, A. Arezzo, M. Caldart, F. Festa and M. Morino "Transanal Endoscopic Microsurgery for Rectal Neoplasms: Experience of 300 Consecutive Cases," Diseases of the Colon \& Rectum, Vol. 52, No. 11, 2009, pp. 1831-1836. doi:10.1007/DCR.0b013e3181b14d2d

[25] B. M. Tsai, C. O. Finne, J. F. Nordenstam, D. Christoforidis, R. D. Madoff and A. Mellgren, "Transanal Endoscopic Microsurgery Resection of Rectal Tumors: Outcomes and Recommendations," Diseases of the Colon \& Rectum, Vol. 53, No. 1, 2010, pp. 16-23. doi:10.1007/DCR.0b013e3181bbd6ee

[26] M. B. Bignell, A. Ramwell, J. R. Evans, N. Dastur and N. L. Simson, "Comlications of Tranasanal Endoscopic Microsurgery (TEMS, a Prospective Audit)," Colorectal Disease, Vol. 12, 2010, pp. e99-103.

[27] M. Cantos, M. Bruna, M. J. García-Coret and F. L. Villalba, "Pneumomediantinum and Subcutaneus Emphysema Like Strange Complications after Transanal Endoscopic Microsurgery," Revista Espanola de Enfermedades Digestivas, Vol. 101, No. 6, 2009, pp. 439-451.

[28] J. S. Moore, P. A. Cataldo, T. Osler and N. H. Hyman, "Transanal Endoscopic Microsurgery Is More Effective than Traditional Transanal Excision for Resection of Rectal Masses," Diseases of the Colon \& Rectum, Vol. 51, No. 7, 2008, pp. 1026-1030. doi:10.1007/s10350-008-9337-X

[29] M. Seman, F. Bretagnol, N. Guedj, L. Maggiori, M. Ferron and Y. Panis, "Transanal Endoscopic Microsurgery (TEM) for Rectal Tumor: The First French SingleCenter Experience," Gastroentérologie Clinique et Biologique, Vol. 34, No. 8-9, 2010, pp. 488-493. doi:10.1016/j.gcb.2009.07.040

[30] N. D. Floyd and T. J. Saclarides, "Transanal Endoscopic Microsurgical Resection of pT1 Rectal Tumors," Diseases of the Colon \& Rectum, Vol. 49, No. 2, 2006, pp. 164-168. doi:10.1007/s10350-005-0269-4

[31] N. Demartines, M. O. von Flue and F. H. Harder, "Transanal Endoscopic Microsurgical Excision of Rectal Tumors: Indications and Results," World Journal of Surgery, Vol. 25, No. 7, 2001, pp. 870-875. doi:10.1007/s00268-001-0043-2

[32] T. Nakagoe, H. Ishikawa, T. Sawai, T. Tsuji, K. Tanaka 
and H. Ayabe, "Surgical Technique and Outcome of Gasless Video Endoscopic Transanal Rectal Tumour Excision," British Journal of Surgery, Vol. 89, No. 6, 2002, pp. 769-774. doi:10.1046/j.1365-2168.2002.02097.x

[33] L. E. Smith, S. T. Ko, T. Saclarides, P. Caushaj, B. A. Orkin and K. S. Khanduja, "Transanal Endoscopic Microsurgery. Initial Registry Results," Diseases of the Colon \& Rectum, Vol. 39, Suppl. 10, 1996, pp. S79-S84. doi:10.1007/BF02053811

[34] W. Lee, D. Lee, S. Choi and H. Chun, "Transanal Endoscopic Microsurgery and Radical Surgery for T1 and T2 Rectal Cancer," Surgical Endoscopy, Vol. 17, No. 8, 2003, pp. 1283-1287. doi:10.1007/s00464-002-8814-x

[35] C. Langer, P. Markus, T. Liersch, L. Füzesi and H. Becker, "UltraCision or High-Frequency Knife in Transanal Endoscopic Microsurgery (TEM)? Advantages of a New Procedure," Surgical Endoscopy, Vol. 15, No. 5, 2001, pp. 513-517. doi:10.1007/s004640090015

[36] G. Winde, H. Nottberg, R. Keller, K. W. Schmid and H. Bünte, "Surgical Cure for Early Rectal Carcinomas (T1). Transanal Endoscopic Microsurgery vs. Anterior Resection," Diseases of the Colon \& Rectum, Vol. 39, No. 9, 1996, pp. 969-976. doi:10.1007/BF02054683

[37] P. Palma, K. Horisberger, A. Joos, S. Rothenhoefer, F. Willeke and S. Post, "Local Excision of Early Rectal
Cancer: Is Transanal Endoscopic Microsurgery an Alternative to Radical Surgery?" Revista Espanola de Enfermedades Digestivas, Vol. 101, No. 3, 2009, pp. 172-178. doi:10.4321/S1130-01082009000300003

[38] M. G. Tytherleigh, B. F. Warren and N. J. Mortensen, "Management of Early Rectal Cancer," British Journal of Surgery, Vol. 95, No. 4, 2008, pp. 409-423. doi: $10.1002 /$ bjs. 6127

[39] S. D. Duek, N. Issa, D. D. Hershko and M. M. Krausz, "Outcome of Transanal Endoscopic Microsurgery and Adjuvant Radiotherapy in Patients with T2 Rectal Cancer," Diseases of the Colon \& Rectum, Vol. 51, No. 4, 2008, pp. 379-384. doi:10.1007/s10350-007-9164-5

[40] E. Lezoche, M. Guerrieri, A. M. Paganini, M. Baldarelli, A. De Sanctis and G. Lezoche, "Long-Term Results in Patients with T2-3 N0 Distal Rectal Cancer Undergoing Radiotherapy before Transanal Endoscopic Microsurgery," British Journal of Surgery, Vol. 92, No. 12, 2005, pp. 1546-1552. doi:10.1002/bjs.5178

[41] M. Guerrieri, M. Baldarelli, L. Organetti, F. Grillo Ruggeri, G. Mantello and S. Bartolacci, "Transanal Endoscopic Microsurgery for the Treatment of Selected Patients with Distal Rectal Cancer: 15 Years Experience," Surgical Endoscopy, Vol. 22, No. 9, 2008, pp. 2030-2035. doi:10.1007/s00464-008-9976-y 